\title{
The question of stimulus content and pupil size
}

\author{
W. SCOTT PEAVLER AND JOHN P. MCLAUGHLIN \\ UNIVERSITY OF DELAWARE
}

Evidence indicated that dilation can be produced, even in the presence of increased luminance, provided the stimulus is sufficiently arousing or novel. The results from a second study failed to support the hypothesis that pupil size is systematically related to rated affect of visually presented words. Possible artifacts of measurement are discussed.

A relationship between psychological attitude and pupil diameter has been proposed in recent work by Hess and his colleagues (Hess, 1965; Hess \& Polt, 1960, 1966; Hess, Seltzer, \& Shlien, 1965). Hess states: ...the evidence suggests that at least with respect to visual material there is a continuum of responses that ranges from extreme dilation for interesting or pleasing stimuli to extreme constriction for material that is unpleasant or distasteful to the viewer. $(1965$, p. 50)

The initial study was performed to determine if the dilation response was capable of overcoming increases in luminance with pictorial material of the type utilized by Hess \& Polt (1960). A second study was designed to test the hypothesis that pupil diameter acts as a bi-directional indicator of positive and negative affect of visually presented stimuli.

Method

The general procedure was to obtain pupillary measures with an apparatus simflar in construction and function to that used by Hess (1965). Ss were presented with a random order of test stimuli, each of which was preceded by a control stimulus equated for luminance. Both test and control stimuli were viewed for $10 \mathrm{sec}$ each. With camera speed regulated at a constant rate of two frames per sec, 20 infrared photographs were obtained for each test and control stimulus. An event marker, recorded on the film, was added to insure an accurate record of stimulus changes. Projection of the processed film onto a translucent screen, which magnified the image by a factor of 20 , permitted pupil diameter to be measured by hand with a millimeter ruler. By comparing the mean diameter of 20 frames associated with a test stimulus with that associated with its control stimulus, it was possible to determine the percent of dilation or constriction occurring in response to each test stimulus.

Experiment 1. Eight college students (four males and four females) were presented with four pictorial stimuli similar to those described by Hess \& Polt (1960). The test stimuli depicted the following: a champagne glass (G); a Picasso painting of horses $(\mathrm{H})$; a movie actress (A); and a female nude "pinup" (N). Control stimuli (blank slides) were developed so that the overall illumination values were $0.6 \mathrm{ft}-\mathrm{c}$ less than the comparable measures of the test stimuli. In addition, the darkest point on a test stimulus was brighter by $0.1 \mathrm{~mL}$ than the brightest point on its corresponding control stimulus. With this arrangement, a constriction response would be expected to each test stimulus, regardless of point of fixation, on the basis of the amount of light reaching the retina.

Experiment 2. In an effort to obtain a quantitative determination of stimulus affect and more accurately control intra-stimulus Illumination than is possible with complex pictorial stimuli, 100 nouns, equated for frequency of occurrence (Heise, 1965), were chosen as stimuli for the second study. Fifty college women were asked to rate the words on two 7-point scales having polar adjectives of "Bad-Good" and "NeutralVery Important." Ratings were complled and divided into three levels (low, 1-2; medium, 3-5; high, 6-7) for each of the two dimensions. Individual 3 by 3 matrices were then complled for each S's ratings of all 100 words. Nineteen Ss had matrices with at least one word in each of the nine cells. These Ss were chosen to participate in the final portion of the study and nine words, one from each of the cells of a S's matrix, were selected to be used as stimuli for that $S$. Test and control stimuli (five Xs) were processed into slides so that the maximum difference in luminance values between them was less than 0.3 $\mathrm{mL}$. Apparatus, procedure, and scoring technique were the same as described above.

Results

Experiment 1. Analysis of the data indicated that the pictorial stimuli produced significant changes in pupil diameter ( $F=4.69, \mathrm{df}=3 / 18, p<.05)$. Further inspection with the Newman-Keuls technique (Winer, 1962) Indicated that the nude stimulus elicited significantly different responses than those associated with the other stimuli $(p<.05)$. The mean response for the nude (N) was $2.2 \%$ dilation while the mean responses for the other test stimuli were all constriction $(\mathrm{G}=6.8 \% ; \mathrm{H}=2.0 \% ; \mathrm{A}=2.0 \%)$ as expected from the brightness differences between test and control stimuli.

Experiment 2. No relationship was found between pupil diameter and rated level of words on either of the two scaled dimensions. Neither percent changes nor absolute changes of pupil diameter proved to be significantly different from zero in any of the nine stimulus conditions.

Discussion

The results from Experiment 1 suggest that the 
dilation response will occur to a stimulus of increased luminance, which would normally result in constriction, if the test stimulus is sufficiently provocative or psychologically arousing such as the nude. This is supported by the extensive investigations performed by Loewenfeld (1958) and the earlier observation made by Bender (1933). Lowenstein \& Loewenfeld (1962) have concluded that cortical, thalamic and hypothalamic impulses produced by sensory and emotional stimuli have an inhibitory effect on the pupillary sphincter and thereby result in dilation.

The lack of a relationship between pupil diameter and rated pleasantness of words in Experiment 2 is in agreement with results reported by Paivio \& Simpson (1966). It can be argued that the words were not provocative enough to produce the dilation responses since there is a considerable amount of recent evidence that dilation is closely associated with stimuli or tasks which produce or require arousal (Beatty \& Kahneman, 1966; Kahneman \& Beatty, 1966, 1967; Nunnally, Knott, Duchnowski, \& Parker, 1967; Paivio \& Simpson, 1966).

This does not, however, explain the lack of evidence for a constriction response to negative stimuli as proposed by Hess (1965). The whole concept of constriction to a stimulus, provided adequate light controls are employed, has been questioned by Loewenfeld (1966). She argues, as a result of extensive physiological investigations, that all psychological and sensory stimuli, other than luminance increments, can dilate the pupil while none of them cause it to contract.

Moreover, the constriction reported by Hess might be artifactual. Woodmansee (1966) has noted that control stimulus baseline diameter frequently varies for different test-control stimulus combinations. A delayed dilation response to a test stimulus or an "anticipation" response during a control stimulus may inflate the control baseline value to such an extent as to bias its use as a neutral comparison for the succeeding test stimulus. Thus "constriction" to a test stimulus could be observed when, in fact, the pupil change reflected a return to the appropriate diameter for the existing light conditions. Other than the work of Hess (1965), this writer knows of no evidence for the aversion-constriction hypothesis. Woodmansee (1967) has failed to demonstrate its existence in repeated attempts.
In summary, while the physiological mechanisms responsible for dilation in response to emotional or novel stimuli are well known, there is at present no further experimental support for Hess' hypothesis that pupil diameter is a bi-directional indicator of stimulus affect. It would seem that a re-examination of the reported phenomenon is in order with a technique free from measurement artifacts such as the shifting control baseline. This would necessitate a procedure whereby pupll diameter could be continuously monitored to insure that the pupil had returned to a "neutral" diameter between presentations of test stimuli.

\section{References}

Beatty, J., \& Kahneman, D. Pupillary changes in two memory tasks. Psychon. Sci., 1966, 5, 371-372.

Bender, W. R. G. The effect of pain and emotional stimuli and alcohol upon pupillary reflex activity. Psychol. Monogr., 1933, 44, 1-32.

Hess, E. H. Attitude and pupil size. Scient. American, 1965, 212, 46-54.

Hess, E. H., \& Polt, J. M. Pupil size as related to interest value of visual stimuli. Science, 1960, 132, 349-350.

Hess, E. H., \& Polt, J. M. Changes in pupil size as a measure of taste difference. Percept. mot. Skills, 1966, 23, 451-455.

Hess, E. H., Seltzer, A. L., \& Shlien, J. M. Pupil response of heter- and homosexual males to pictures of men and women: a pilot study. J. abnorm. Psychol., 1965, 70, 165-168.

Heise, D. R. Semantic differential profiles for 1,000 most frequent English words. Psychol. Monogr., 1965, 79, 1-31.

Kahneman, D., Beatty, J. Pupil diameter and load on memory. Science, 1966, 154, 1583-1585.

Kahneman, D., \& Beatty, J. Pupillary responses in a pitch-discrimination task. Percept. \& Psychophys., 1967, 2, 101-105.

Loewenfeld, I. E. Mechanisms of reflex dilatation of the pupil. Historical review and experimental analysis. Documenta Opthalmologica, 1958, 12, 185-448.

Loewenfeld, I. E. Pupil size. Surv. Ophthal., 1966, 11, 291-294.

Lowenstein, 0., \& Loewenfeld, I. E. The pupil. In H. Davson (Ed.), The eye. New York: Academic Press, 1962, Vol. 3. Pp. 231-267.

Nunnally, J. C., Knott, P. D., Duchnowski, A., \& Parker, R. Pupillary response as a general measure of activation. Percept. \& Psychophys., 1967, 2, 149-155.

Paivio, A., \& Simpson, H. M. The effect of word abstractness and pleasantness on pupil size during an imagery task. Psychon. Sci., 1966, 5, 55-56.

Winer, B. J. Statistical principles in experimental design. New York: McGraw-Hill, 1962.

Woodmansee, J. J. Methodological problems in pupillographic experiments. Proc. 74th Annu. Conv. Amer. Psychol. Assoc., $1966,133-134$.

Woodmansee, J. J. Personal communication, 1967. 